\title{
TRIBUNAL CONSTITUCIONAL Vs. PODER JUDICIAL (A PROPÓSITO DE UN PROCESO COMPETENCIAL)
}

\author{
VÍCTOR MALPARTIDA CASTILLO*
}

\begin{abstract}
Resumen
Las fricciones entre el Poder Judicial y el Tribunal Constitucional no son nada nuevo dentro del derecho comparado. Como recuerda García Belaúnde han existido por lo menos desde la década del sesenta en Italia, de donde nos viene el nombre de "Guerra de las Cortes", ya que el máximo órgano judicial en el mencionado país es la denominada Corte de Casación y el órgano de control constitucional concentrado se llama Corte Constitucional. Dicho fenómeno se repetiría en España y también en Colombia, en donde se conoce al incidente como "choque de trenes". En nuestro país, discutir si el Tribunal Constitucional es jerárquicamente superior respecto al Poder Judicial es hacer mención de los alcances del artículo $201^{\circ}$ de la Constitución vigente que define al primero como autónomo e independiente y como "el órgano de control de la Constitución".
\end{abstract}

Pero, en estricta relación con lo señalado, este trabajo también hace un tratamiento del precedente vinculante, figura que a partir del Código Procesal Constitucional se introdujo en el artículo VII de su Título Preliminar y que el Tribunal Constitucional en su Sentencia $N^{\circ} 0024-2003-\mathrm{AI} / \mathrm{TC}$ ha definido como "aquella regla jurídica expuesta en un caso particular y concreto que el Tribunal Constitucional decide establecer como regla general; y, que por ende, deviene en parámetro normativo para la resolución de futuros procesos de naturaleza homóloga", y que por tanto, "el precedente constitucional tiene por su condición de tal, efectos similares a una ley. Es decir, la regla general externalizada como precedente a partir de un caso concreto se convierte en una regla preceptiva común que alcanza a todos los justiciables y que es oponible frente a los poderes públicos". Finalmente, se plantea una reflexión acerca de la cosa juzgada constitucional.

Palabras clave: Competencia del Tribunal Constitucional - Competencia del Poder Judicial - Guerra de Cortes - Intérprete supremo de la constitución Precedente vinculante - Cosa juzgada constitucional.

\begin{abstract}
In comparative law, frictions between the Judiciary and the Constitutional Tribunal are not new. As Garcia Belaunde recalls they have existed since the 60 's in Italy, from where the name "Battle of the Courts" originated, because the maximum judicial body in said country is the Court of Cassation and the concentrated body for constitutional control is the Constitutional Tribunal. The aforementioned phenomenon is replicated in Spain and in Colombia, where the incident is known as a "train crash". In our country, to debate
\end{abstract}

\footnotetext{
* Juez Superior Titular de la Corte Superior de Justicia de Ica-Poder Judicial del Perú. Profesor de la Universidad Nacional Mayor de San Marcos.
} 
Víctor Malpartida Castillo - Tribunal Constitucional vs. Poder Judicial

(A propósito de un proceso competencial)

whether the Constitutional Tribunal is hierarchically superior to the Judiciary is to mention the scope of Article $201^{\circ}$ of the Constitution in force that defines the Constitutional Tribunal as the autonomous and independent "controlling body of the Constitution".

However and strictly in relation to the foregoing, this article also tackles the binding precedent, a figure that was introduced in Article VII of the Preliminary Title of the Constitutional Procedural Code and that the Constitutional Tribunal, in its Judgment No. 0024-2003-A1/TC, defined as "it is a legal rule in a specific and particular case which the Constitutional Tribunal decides to establish as a general rule", thereby becoming a normative parameter for the resolution of future similar proceedings. In consequence, due to its very condition, the constitutional precedent has similar effects to those of a law. In other words, "the general rule established as a precedent based on a specific case becomes a common precept for all defendants which is effective against the public powers". Finally, it proposes a reflection of the constitutional res judicata.

Key words: Jurisdiction of the Constitutional Tribunal - Jurisdiction of the Judiciary - Battle of the Courts - Supreme interpreter of the Constitution binding precedent - Constitutional res judicata.

\section{Sumario}

1. Introducción. 2. Tribunal Constitucional y Poder Judicial: ¿Guerra de las Cortes? 3. A propósito de un proceso competencial. 3.1. Introducción. 3.2. Reconstrucción de la resolución 3.2.1. Aspectos generales. 3.2.2. Argumentos del Tribunal: afectación de las atribuciones constitucionales del Poder Ejecutivo de cumplir y hacer cumplir las leyes, y, cumplir y hacer cumplir las resoluciones y sentencias de los órganos jurisdiccionales. 3.2.3. Análisis de los argumentos del Tribunal. 3.2.4. Aspectos esenciales de la sentencia. 3.2.4.1. ¿Es el Tribunal Constitucional el intérprete supremo de la Constitucion y jerárquicamente superior? 3.2.4.2. Precedentes constitucionales vinculantes. 3.2.4.3. Cosa juzgada constitucional. 4. Aspectos conclusivos.

\section{INTRODUCCIÓN}

A medida que se ha desarrollado la labor del Tribunal Constitucional peruano, se han ido presentando fricciones entre su labor y la que cumple el Poder Judicial, que en mucho nos lleva a pensar en una asfixia de éste último poder del Estado. Esto propicia preguntarnos sobre cuáles son los límites entre una y otra institución dentro del Estado y cuáles son los parámetros establecidos en la Constitución Política vigente.

Dichas fricciones entre dos poderes constituidos -Poder Judicial y Tribunal Constitucional- no es nada nuevo. Como recuerda Domingo García Belaunde 
Víctor Malpartida Castillo - Tribunal Constitucional vs. Poder Judicial

(A propósito de un proceso competencial)

han existido por lo menos desde la década del sesenta en Italia ${ }^{1}$, de donde nos viene el nombre de "Guerra de las Cortes", ya que el máximo órgano judicial en el mencionado país es la denominada Corte de Casación y el órgano de control constitucional concentrado se llama Corte Constitucional. Dicho fenómeno se repetiría en España ${ }^{2}$ y también en Colombia, en donde se conoce al incidente como "choque de trenes" 3 .

En la Sentencia del Tribunal Constitucional en el Expediente 006-2006$\mathrm{PC} / \mathrm{TC}$, se resumen y culminan muchos de los aspectos que representan los roces o fricciones que a lo largo de estos años se han generado entre el Tribunal Constitucional y el Poder Judicial. De allí, la necesidad de analizarlos dentro de un contexto que involucra una concepción institucional muy marcada del primero sobre una democracia constitucional y su rol en ella.

\section{TRIBUNAL CONSTITUCIONAL Y PODER JUDICIAL: ¿GUERRA DE LAS CORTES?}

Cuando se analizan los pronunciamientos del Tribunal Constitucional peruano, se encuentran, en esencia, los términos en los cuales se basa la forma cómo se relaciona con la judicatura ordinaria.

Así, se tieneal principio dela "autonomía procesal" del Tribunal Constitucional, que se ha proyectado en un actuar concreto de la mencionada institución. Como proyección de la "autonomía procesal" del Tribunal Constitucional se tiene un despliegue no solo en lo que respecta al Reglamento Normativo

\footnotetext{
1 Francisco Javier Díaz Revorio señala en relación a Italia: "Pero en cualquier caso la experiencia italiana pone de manifiesto otros problemas que son aplicables a la mayoría de los Estados que cuentan con un sistema de jurisdicción constitucional concentrada en un órgano específico y distinto al que se sitúa a la cabeza del Poder Judicial. Y es que es fácil que se produzcan conflictos cuando unos órganos son soberanos en la interpretación de la ley(entre los cuales uno posee además una específica función de unificación de la interpretación legal), y otro es el máximo intérprete constitucional, lo que incluye como consecuencia que su "interpretación constitucional de la ley" tienda a imponerse o prevalecer sobre la que cualquier juez pueda hacer".(Díaz Revorio, Francisco Javier: Interpretación de la Constitución y Justicia Constitucional. Editorial Porrúa. México 2009, p. 242).

2 Díaz Revorio en relación a lo ocurrido en España señala: "Y en efecto, aunque no es posible realizar un examen exhaustivo de todas las leyes que han sido objeto de interpretación por el Tribunal Constitucional en las sentencias que resuelven procedimientos de inconstitucionalidad - tanto en sentencias interpretativas como de otro tipo -, parece que en la generalidad de los casos el Tribunal Supremo ha aceptado las interpretaciones legales del supremo intérprete de la Constitución, y por su parte éste solo ha indicado cuál debe ser la interpretación de la ley cuando los preceptos constitucionales imponían esa interpretación. $\mathrm{O}$ al menos, no ha habido "roces" o conflictos significativos por este motivo" (Ibidem, p. 248).

3 García Belaunde, Domingo: «Presentación». En: ¿Guerra de las Cortes? A propósito del proceso competencial entre el Poder Ejecutivo y el Poder Judicial. Coordinador: Domingo García Belaunde. Palestra del Tribunal Constitucional 4. Cuadernos de Análisis y Crítica a la Jurisprudencia Constitucional. Editorial Palestra, Lima 2007, p. 8.
} 
del órgano contralor, sino sobre todo a través de sus resoluciones. Es el propio César Landa quien explica las manifestaciones que ha tenido dicha "autonomía procesal" del Tribunal Constitucional, a través de la acción, la jurisdicción y el proceso. No obstante lo expuesto por César Landa, en cuanto a la proyección en el actuar del Tribunal Constitucional de la "autonomía procesal", lo cierto es que existen líneas de desarrollo que emprendió el órgano de control constitucional concentrado, en las que también se evidencia la proyección de la "autonomía procesal", o, al menos, dichas líneas son la consecuencia del pensar en el rol del Tribunal.

Se encuentran dos marcadas líneas de acción en cuanto a la relación existente entre el Tribunal Constitucional y el Poder Judicial. Una línea se identifica con la reconducción del trámite de ciertas pretensiones hacia la judicatura ordinaria mediante medios ordinarios de tutela, no a través de procesos constitucionales, y, como consecuencia de ello, sea el Poder Judicial quien en exclusividad conozca temas que antes eran competencia del Tribunal Constitucional. En este punto resultan importantes los casos: Exp. 1417AA/TC(Caso Manuel Anicama Hernández), Exp. 0168-2005- PC/TC(Caso Maximiliano Villanueva Valverde), Exp. 0206-2005- PA/TC(Caso César Baylón Flores).

Por otra parte, la segunda línea de acción, está relacionada con el control de constitucionalidad sobre resoluciones judiciales. En éste desarrollo del Tribunal resulta de interés lo establecido en los casos: Exp. 3846-2004-PA/ TC (Caso Municipalidad Provincial de San Pablo), Exp. 3179-2004-AA/TC (Caso Apolonia Ccollcca Ponce), Exp. 4853-2004-PA/TC(Caso Dirección Regional de Pesquería de La Libertad), así como el Exp. 006-2006-CC/TC (Caso Ministerio de Comercio Exterior y Turismo contra el Poder Judicial). A los anteriores se suma lo establecido en los casos: Exp. 03173-2008-HC/ TC (Caso Teodorico Bernabé Montoya), Exp. 03908-2007-PA/TC (Caso Provías Nacional). Como anota Eloy Espinosa al respecto, "(...)si algo tienen en común estas sentencias, emitidas como precedente vinculante, es que apuntan a configurar un escenario en el cual se busca consagrar un control prácticamente total de la actuación de la judicatura ordinaria por el Tribunal Constitucional, bajo parámetros que en puridad parecieran ir más allá que aquellos que permitiría la normatividad actualmente vigente al respecto" ${ }^{\prime 4}$.

\footnotetext{
4 EsPinOSA-SALDAÑA BARRERA, Eloy. «El Juez Constitucional y sus márgenes de acción frente a la judicatura ordinaria: algunas reflexiones a propósito de las relaciones entre el Tribunal Constitucional y el Poder Judicial en el Perú». En: AA. VV. Memoria del X Congreso Iberoamericano de Derecho Constitucional (Lima 16-19 de Septiembre de 2009). Tomo II. Lima, 2009, p. 543.
} 
Víctor Malpartida Castillo - Tribunal Constitucional vs. Poder Judicial

(A propósito de un proceso competencial)

La sentencia en análisis en el presente capítulo no es otra cosa que la culminación de ese actuar del Tribunal Constitucional y, asimismo, de la proyección del principio de "autonomía procesal".

\section{A PROPÓSITO DE UN PROCESO COMPETENCIAL}

\subsection{Introducción}

Siendo la resolución más importante por los alcances expresados en cuanto a la relación entre el Tribunal Constitucional y el Poder Judicial, es necesario haberle reservado un análisis diferenciado a la Sentencia del Tribunal Constitucional en el Expediente 006-2006-PC/TC.

El proceso competencial analizado se inicia por demanda del Ministerio de Comercio Exterior y Turismo y, el Poder Judicial, como demandado, por considerar el primero, que en sede judicial, se vienen afectando las esferas de competencia del Poder Ejecutivo, concretamente, el artículo $118^{\circ}$, incisos 1 y 9 de la Constitución, así como el artículo $121^{\circ}$ y $128^{\circ}$ de la Carta Magna.

\subsection{Reconstrucción de la resolución}

\subsubsection{Aspectos generales}

El proceso competencial se inicia por demanda interpuesta por el Ministerio de Comercio Exterior y Turismo contra el Poder Judicial, solicitando: 1.- Que se determine si el Poder Judicial tiene la facultad de declarar inaplicables normas legales que regulan la actividad de juegos de casinos y máquinas tragamonedas, cuya constitucionalidad ha sido ratificada por el Tribunal Constitucional en reiterados pronunciamientos; 2 .- Que se declare la nulidad de diversas resoluciones judiciales recaídas en procesos de amparo y de cumplimiento, incluyendo algunas ya en calidad de cosa juzgada.

El Ministerio de Comercio Exterior y Turismo fundamenta su demanda en que después de la promulgación de la legislación que regula la actividad de juegos de casino y máquinas tragamonedas, ciertos grupos empresariales recurrieron al Poder Judicial con el objeto de sustraerse de los alcances de dicha regulación, principalmente mediante la interposición de procesos constitucionales de amparo. Que, no obstante existir la mencionada legislación que faculta al mencionado Ministerio para ser competente en cuanto a la actividad económica de casinos y máquinas tragamonedas, lo cierto es que el 
Víctor Malpartida Castillo - Tribunal Constitucional vs. Poder Judicial

(A propósito de un proceso competencial)

Poder Judicial, mediante sus resoluciones otorga licencias de funcionamiento, pese a que ello implica dejar sin efecto normas convalidadas por el Tribunal Constitucional e, incluso, han implementado plazos de adecuación distintos a los que la ley confiere.

El Poder Judicial respondiendo a la demanda, señala que la entidad demandante quiere la revisión de sentencias judiciales que han adquirido la calidad de cosa juzgada y que, por tanto, son inmodificables, irrevisables y de obligatorio cumplimiento. Señala además, que la demandante pudo interponer en los procesos acabados, los respectivos recursos impugnatorios regulados en cada uno de los procesos; y, asimismo, que se ha limitado el Poder Judicial a ejercer legítimamente sus atribuciones constitucionales, y que igualmente, mediante el proceso competencial instaurado se está afectando su independencia.

\subsubsection{Argumentos del Tribunal: afectación de las atribuciones constitucionales del Poder Ejecutivo de cumplir y hacer cumplir las leyes, $y$, cumplir y hacer cumplir las resoluciones y sentencias de los órganos jurisdiccionales}

Son dos las afectaciones que el Tribunal Constitucional señala como las producidas en las atribuciones del Poder Ejecutivo. En primer lugar, la afectación en lo concerniente a la atribución establecida en el artículo $118^{\circ}$ inciso 1 de la Constitución, en el cual se prescribe que corresponde al Presidente de la República: "Cumplir y hacer cumplir la Constitución y los tratados, leyes y demás disposiciones legales". Y, asimismo, se plantea la afectación producida en lo concerniente a la atribución del Poder Ejecutivo de "cumplir y hacer cumplir las resoluciones y sentencias de los órganos jurisdiccionales", establecida en el artículo $118^{\circ}$ inciso 9 de la Carta Magna.

En primer lugar, en relación a la afectación de la atribución constitucional del Poder Ejecutivo de cumplir y hacer cumplir la Constitución y las leyes, se debe tener en cuenta que la Ley $\mathrm{N}^{\circ} 27153$ fue cuestionada por medio de una demanda de inconstitucionalidad, y el Tribunal declaró fundada en parte la demanda -STC 009-2001-AI/TC-, y, "con ello la inconstitucionalidad de los artículos $38^{\circ}$, inciso $1,39^{\circ}$, Primera y Segunda Disposición Transitoria y, por conexidad, el artículo $1^{\circ}$ de la Ley 27232, refrendando la constitucionalidad de sus demás disposiciones". En este mismo apartado, el Tribunal hace la indicación que esta sentencia, mereció la intervención del legislador a través de la Ley $\mathrm{N}^{\circ} 27796$, a fin de proveerla de la conformidad reclamada. (Fundamento Jurídico 30)). 
Víctor Malpartida Castillo - Tribunal Constitucional vs. Poder Judicial

(A propósito de un proceso competencial)

Asimismo, citando el Tribunal Constitucional el precedente vinculante habido en la STC 4227-2005-AA/TC, en el cual se señala que al haberse confirmado la constitucionalidad del artículo $17^{\circ}$, y la Tercera y Décima Disposiciones Transitorias de la Ley 27796 y de una variada normatividad, "en aplicación del primer párrafo del artículo VI del Código Procesal Constitucional -que resulta también de aplicación en aquellos casos en los que este colegiado desestima la solicitud de ejercer el control difuso contra norma, por no encontrar en ella vicio alguno de inconstitucionalidad-dichos preceptos resultan de plena aplicación en todo tipo de procesos, quedando proscrita su inaplicación por parte de los jueces en ejercicio del control difuso de constitucionalidad de normas".

De allí que el Tribunal en relación siempre a la afectación de la atribución del Poder Ejecutivo de cumplir y hacer cumplir las leyes, señale que "al Poder Ejecutivo le corresponde ejercer su atribución constitucional de hacer cumplir, efectivamente, la Ley 27153, modificado por la Ley 27796"(Fundamento Jurídico 32). Por ello en este punto añade: “De ahí que la estimación, ilegítima, de las demandas de amparo y de cumplimiento por parte del Poder Judicial, en el ejercicio de su función jurisdiccional, comporta un menoscabo de la atribución del Poder Ejecutivo para cumplir y hacer cumplir las leyes que la Constitución le reconoce" (Fundamento Jurídico 34).

Por otra parte, en cuanto a la afectación de la atribución del Poder Ejecutivo de hacer cumplir las resoluciones judiciales y sentencias de los órganos jurisdiccionales, se tiene que debe hacer cumplir "la sentencia del Tribunal Constitucional 009-2001-AI/TC y el precedente vinculante establecido en la sentencia 4227-2005-AA/TC tal como expresamente lo prevé el artículo 118 , inciso 9 de la Constitución".

Ahora bien, fundamentando lo dicho, el Tribunal -en relación a la STC 0092001-AI/TC- señala que "las sentencias de inconstitucionalidad de una norma legal emitidas por el Tribunal Constitucional tienen una triple identidad: fuerza de ley, cosa juzgada y vinculan a todos los poderes públicos. La afirmación de que la sentencia de inconstitucionalidad de una ley, por su carácter de cosa juzgada, tiene efectos vinculantes u obligatorios para los poderes públicos, se deriva del carácter general que produce los efectos derogatorios de su sentencia..."(Fundamento Jurídico 39). Lo anterior queda remarcado con lo siguiente: "El juez ordinario no puede ampararse en su independencia para desvincularse de las sentencias del Tribunal Constitucional, pues ello significaría, en último término, una vulneración de la propia Constitución. Ello pone en evidencia, además, los límites constitucionales de la facultad 
Víctor Malpartida Castillo - Tribunal Constitucional vs. Poder Judicial

(A propósito de un proceso competencial)

de ejercer el control difuso que reconoce el artículo $138^{\circ}$ de la Constitución. En definitiva uno de los límites del ejercicio del control difuso judicial lo constituyen las sentencias y los precedentes vinculantes de este Colegiado(... )"(Fundamento Jurídico 46).

Por otro lado, en cuanto al precedente vinculante dictado en la sentencia en el Exp. 4227-2005-AA/TC, "es menester indicar que también se ha afectado la atribución constitucional del Poder Ejecutivo de cumplir y hacer cumplir las resoluciones de los órganos jurisdiccionales [...] En este caso, la ilegitimidad constitucional de la estimación de las demandas de amparo y de cumplimiento por parte del Poder Judicial, en detrimento del Poder Ejecutivo, es aún más notoria" (Fundamento Jurídico 48).

Se explica seguidamente que en la sentencia en el Exp. 4227-2005-AA/TC, al confirmarse varias disposiciones, dichos preceptos resultan de plena aplicación en todo tipo de procesos, quedando proscrita su inaplicación por parte de los jueces en ejercicio del control difuso de constitucionalidad de las normas. A ello -agrega la sentencia en comento- se debe tener en cuenta que los jueces son independientes y autónomos en el ejercicio de la función jurisdiccional, pero "su actuación será constitucional solo si respetan las relaciones entre los poderes del Estado y los órganos constitucionales". Por tanto, "si el constituyente, en nuestro ordenamiento, ha decidido consagrar al Tribunal Constitucional como guardián de los derechos fundamentales y órgano supremo "de control de la Constitución" (artículo 201), entonces, si bien no es el único intérprete, a él le corresponde decir la última palabra de lo que es o no constitucional, y ningún poder u órgano constitucional puede contradecirlo o desvincularse de sus decisiones, sino a costa de poner en cuestión nuestro sistema de justicia constitucional y el sistema democrático mismo" (Fundamento Jurídico 52).

Concluye sobre el particular que al estimar las demandas de amparo y de cumplimiento, el Poder Judicial desconoce los efectos normativos de las sentencias mencionadas y menoscaba la atribución constitucional establecida para el Poder Ejecutivo en el artículo $118^{\circ}$ inciso 9.

Asimismo, dos aspectos finales resultan interesantes en la sentencia en análisis. El primero tiene que ver con la consecuente nulidad de las resoluciones y sentencias que han estimado las demandas de amparo o de cumplimiento con desconocimiento de las sentencias a las que se ha aludido anteriormente. Resulta interesante pues el Tribunal señala que al ser sus sentencias "concreciones de la Constitución que se incorporan al sistema de 
Víctor Malpartida Castillo - Tribunal Constitucional vs. Poder Judicial

(A propósito de un proceso competencial)

fuentes, son parámetros jurídicos para evaluar la legitimidad constitucional de los actos legislativos, administrativos e, incluso, jurisdiccionales. Su omisión o desvinculación por parte de cualquier poder del Estado u órgano constitucional acarrea, prima facie su nulidad. Ello es precisamente lo que determina, en el presente caso, la ilegitimidad de las resoluciones estimatorias de amparo y cumplimiento expedidas por el Poder Judicial; lo que finalmente causa un detrimento en las atribuciones del Poder Ejecutivo ya aludidas supra". (Fundamento Jurídico 62).

El segundo aspecto a resaltar es sobre la "cosa juzgada constitucional". Se invoca este concepto en cuanto sirve al Tribunal para descartar que al anular las resoluciones en los procesos de amparo y cumplimiento se está afectando la cosa juzgada. Se señala que lo que la Constitución garantiza, a través del artículo $139^{\circ}$ inciso 2 es la "cosa juzgada constitucional", la que se configura con aquella sentencia que se pronuncia sobre el fondo de la controversia jurídica, de conformidad con el orden objetivo de valores, con los principios constitucionales y con los derechos fundamentales, y de acuerdo con la interpretación que haya realizado el Tribunal Constitucional de las leyes, o de toda norma con rango de ley, o de los reglamentos y de sus precedentes vinculantes, como lo prescriben los artículos VI y VII del Título Preliminar del Código Procesal Constitucional, respectivamente.

Con la cosa juzgada constitucional se cierra una serie de argumentos que, repetimos, van a constituir la culminación de una línea de desarrollo doctrinal del Tribunal Constitucional. Así, como aspectos propios de la sentencia en análisis en el presente proceso competencial, van a estar los argumentos que serán tratados en el siguiente acápite. Pero también es necesario, más allá de estos últimos, detenernos en conceptos como la "relación de grado inferior", del Poder Judicial con respecto al Tribunal Constitucional expuesto(Fundamento Jurídico 51 y 52); también lo concerniente a la manera como se asumen los precedente vinculantes constitucionales; y, finalmente la propia "cosa juzgada constitucional". Existen otros aspectos interesantes de analizar pero entre ellos nos parecen esencialmente analizables los mencionados.

\subsubsection{Análisis de los argumentos del Tribunal}

Siguiendo en esto a Castillo Córdova, tenemos que coincidir en cuanto a dejar establecido que la función de control difuso de la constitucionalidad por parte de los magistrados del Poder Judicial en cuanto a la Ley 27153 y la Ley 27796 no ha quedado anulada, pudiendo dichos magistrados inaplicar dichos dispositivos. 
Así, en lo que respecta a la Ley 27153, el autor citado señala que podrá ser objeto de control, al menos respecto de dos tipos de preceptos: "El primero está referido de aquellos preceptos que no fueron cuestionados a través de la demanda de inconstitucionalidad. Estos preceptos no solo se encuentran plenamente vigentes, sino que adicionalmente sobre ellos no ha habido una confirmación de su constitucionalidad por parte del Tribunal Constitucional $\mathrm{y}$, consecuentemente, respecto de ellos no es posible exigir el deber de aplicación contenido en el segundo párrafo del artículo VI CPConst: "Los Jueces no pueden dejar de aplicar una norma cuya constitucionalidad haya sido confirmada en un proceso de inconstitucionalidad"".

Castillo Córdova argumenta así: "En efecto, como se recordará, la demanda de inconstitucionalidad que dio origen a la sentencia al EXP. No 009-2001$\mathrm{AI} / \mathrm{TC}$, no fue interpuesta contra todos los dispositivos de la Ley 27153, sino solo contra algunos de ellos. De modo que cuando el Tribunal Constitucional resuelve declarando inconstitucionales algunos preceptos de la mencionada ley, los únicos preceptos que quedan confirmados en su constitucionalidad son los dispositivos cuestionados y examinados en su constitucionalidad y no declarados inconstitucionales. Sobre el resto de los dispositivos los jueces del Poder Judicial son competentes para examinarlos en su constitucionalidad y decidir inaplicarlos en un caso concreto de encontrarlos inconstitucionales" ${ }^{\prime \prime}$.

Ahora bien, en cuanto al segundo grupo de preceptos -siguiendo al autor mencionado-, "está conformado por aquellos preceptos de la Ley 27153 que han sido cuestionados en su constitucionalidad, y respecto de los cuales el Supremo intérprete de la Constitución ha decidido confirmar su constitucionalidad, y lo ha hecho en referencia a determinados preceptos de la Constitución". Señala Castillo Córdova, fundamentando lo anterior que: "En efecto, si en la sentencia de inconstitucionalidad el mencionado Alto Tribunal declara que un precepto legal es constitucional porque no vulnera determinado artículo de la Constitución(regla o principio o valor o bien jurídico constitucional), lo único que vincula al juez que resuelva casos posteriores es la declaración de constitucionalidad del precepto legal en relación al artículo de la Constitución que sirvió de parámetro de evaluación. De modo que el juez del Poder Judicial podrá inaplicar el mismo precepto legal declarado constitucional en un proceso de inconstitucionalidad si llega a considerar que en un caso concreto la aplicación de ese precepto resulta inconstitucional por vulnerar un distinto precepto de la Constitución" ${ }^{\prime \prime}$.

\footnotetext{
5 CAstillo CóRdova, Luis. El Tribunal Constitucional y su dinámica jurisprudencial. Lima: Editorial Palestra., 2008, pp. 232-233.

6 Ibid., pp. 233-234.
} 
Víctor Malpartida Castillo - Tribunal Constitucional vs. Poder Judicial

(A propósito de un proceso competencial)

Por lo anterior, entonces, se coincide plenamente cuando se afirma que el Tribunal no acierta porque "la confirmación de constitucionalidad no se puede predicar de modo general respecto de todas las disposiciones de la Ley 27153 no declaradas inconstitucionales" ${ }^{\prime 7}$. Sin embargo, el órgano de control constitucional señala: "El Tribunal Constitucional declaró fundada en parte la demanda (refiriéndose a la sentencia en el EXP. $N^{o}$ 009-2001-AI/TC) y, con ello, la inconstitucionalidad de los artículos $38^{\circ}$, inciso $1,39^{\circ}$, Primera y Segunda Disposición Transitoria y, por conexidad, el artículo $1^{\circ}$ de la Ley 27232, refrendando la constitucionalidad de sus demás disposiciones"(Fundamento Jurídico 30).

Asimismo, respecto de la Ley 27796, se puede decir que al darse la demanda de inconstitucionalidad -que va a dar lugar a la sentencia al EXP. $\mathrm{N}^{0} 009$ 2001-AI/TC- en relación a la Ley 27153 y no la Ley 27796, entonces "los jueces y magistrados del Poder Judicial no pierden su competencia para examinar la constitucionalidad del texto reformado de esos mismo preceptos" como anota Castillo Córdova; sin embargo, existe una excepción a la regla antes dicha, vale decir, será posible extender la confirmación de constitucionalidad de un texto original hacia el texto modificado, solo cuando del examen y de la confirmación del texto original es posible extraer una regla plenamente aplicable al texto modificado ${ }^{8}$.

Como conclusiones de esta parte, en cuanto a que si lo jueces se han extralimitado en el ejercicio de su función jurisdiccional a la hora de inaplicar preceptos de la Ley 27153 que no habían sido declarados inconstitucionales por el Tribunal en la sentencia en el EXP. No 009-2001-AI/TC, se tiene: "La primera, negar que los jueces del Poder Judicial se encontraban impedidos de evaluar la constitucionalidad de los preceptos de la Ley 27153 tanto en su texto original como en su texto modificado por la Ley 27796 y por la Ley 28945. Segunda, los jueces podían examinar la constitucionalidad de los preceptos de la Ley 27153 que no fueron confirmados en su constitucionalidad en la referida sentencia al EXP. No 009-2001-AI/TC. Tercera, podían también evaluar la constitucionalidad de los preceptos de la Ley 27153 confirmados en su constitucionalidad en esta sentencia, siempre y cuando el juicio de constitucionalidad se realizase con respecto a normas de la Constitución distintas a las que sirvieron de parámetro para confirmar su constitucionalidad. Cuarta, podían examinar también la constitucionalidad de la Ley 27796, ya que esta no ha sido objeto de cuestionamiento a través de una demanda de

Ibid., p. 235.

$8 \quad$ Ibid., pp. 237.238. 
Víctor Malpartida Castillo - Tribunal Constitucional vs. Poder Judicial

(A propósito de un proceso competencial)

inconstitucionalidad tal y como lo exige el segundo párrafo del artículo VI CPConst., sin embargo, el juicio de constitucionalidad que sobre ella realicen los jueces debe sujetarse a los criterios jurisprudenciales presentados por el Tribunal Constitucional en los fundamentos a la sentencia al EXP. $\mathrm{N}^{\mathrm{o}}$ 0092001-AI/TC, en lo que sea pertinente por así exigirlo el tercer párrafo del artículo VI CPConst." ${ }^{\prime \prime}$.

Igualmente, Castillo Córdova hace una salvedad en cuanto a que los jueces no podían ejercer un control difuso en cuanto a los preceptos de la Ley 27153 que fueron declarados constitucionales $\mathrm{y}$, asimismo, si la inaplicación es en base a los mismos artículos de la Constitución que fueron empleados por el Tribunal para declarar la constitucionalidad de los referidos preceptos. Concluyendo esta parte, el autor citado remarca que no se puede saber, por falta de fundamentación en la sentencia en el Exp. 006-2006-PI/TC, si las resoluciones y sentencias que fueron declaradas nulas se apoyaban en los casos en que no podían los jueces inaplicar los preceptos, antes mencionados ${ }^{10}$.

Por otra parte, en lo que toca a si los jueces del Poder Judicial han incurrido en un ejercicio extralimitado de la función judicial a la hora de inaplicar el artículo 17, Primera y Décima Disposición Transitoria de la Ley 27796, debido a que según la sentencia al EXP. No 4227-2005-AA/TC, constituía precedente vinculante la confirmación de constitucionalidad de estos preceptos legales, se tienen las siguientes conclusiones expuestas por Castillo Córdova: "Primera, que los referidos preceptos de la Ley 27796 no han sido declarados constitucionales en un proceso de inconstitucionalidad, sino en un proceso de amparo, por lo que no puede reconocérsele un efecto erga omnes, propio del producto jurisprudencial recogido en el segundo párrafo del artículo VI CPConst. Segunda, la constitucionalidad examinada y declarada por el Tribunal Constitucional en la sentencia al EXP. No 4227-2005-AA/ TC ha sido en referencia a las concretas circunstancias del demandante de amparo. Tercera, esta constitucionalidad podría extrapolarse solamente a otros casos sustancialmente semejantes. Cuarta, es el juez del Poder Judicial el que tiene que examinar y decidir cuales casos futuros son sustancialmente semejantes"11.

Aclara seguidamente el autor citado que: "Como consecuencia de esto, no es verdad -como mal refiere el Tribunal Constitucional- que haya quedado siempre proscrita la inaplicación de los artículos 17, primera y décima

\footnotetext{
9 Ibid., p. 240.

10 Ibid., p. 241.

11 Ibid., p. 248.
} 
Víctor Malpartida Castillo - Tribunal Constitucional vs. Poder Judicial

(A propósito de un proceso competencial)

disposición transitoria de la Ley 27796 para los concretos casos futuros, por lo que no es verdad que deban ser consideradas nulas todas aquellas resoluciones judiciales en las que se ha inaplicado el precedente vinculante. El juez ha mantenido plenamente la facultad de revisar la constitucionalidad de los mencionados dispositivos legales y -eventualmente- inaplicarlos. Por lo tanto, el juez no ha incurrido necesariamente en inconstitucionalidad por exceso en el ejercicio de su función jurisdiccional, cuando ha declarado inaplicables algunos de estos preceptos legales en las demandas de amparo resueltas con posterioridad a la sentencia al EXP. No 4227-2005-AA/TC"12.

\subsubsection{Aspectos esenciales de la sentencia}

Como se ha señalado anteriormente, existen aspectos esenciales en esta sentencia que deben ser tratados de manera especial como el considerar jerárquicamente superior al Tribunal Constitucional en relación al Poder Judicial; asimismo, lo respectivo sobre los precedentes vinculantes; $\mathrm{y}$, finalmente en lo referente a la cosa juzgada constitucional.

\subsubsection{1. ¿Es el Tribunal Constitucional el intérprete supremo de la Constitución y jerárquicamente superior?}

Enla Constitución vigente, en el artículo $201^{\circ}$ se defineal Tribunal Constitucional como autónomo e independiente, pero así mismo se prescribe que "es el órgano de control de la Constitución". Este texto constitucional repite lo que se había establecido para el Tribunal de Garantías Constitucionales, en la Constitución de 1979.

Comentando ambas constituciones, Eguiguren Praeli ${ }^{13}$ sostiene que en la primera no se le atribuye la calidad de "supremo intérprete" de la Constitución, por lo menos no expresamente, mientras que en relación a la vigente, aunque se repite la misma definición, al leerla sistemáticamente con la Primera de las Disposiciones Generales de la Ley Orgánica del Tribunal Constitucional pasada -hoy derogada ${ }^{14}$ - con los artículos $39^{015} \mathrm{y}$

12 Ibid., p. 249.

13 Eguiguren Praeli, Francisco. «Relaciones entre el Poder Judicial y el Tribunal Constitucional en el Perú: La evolución del Modelo y los nuevos problemas». En: Pensamiento Constitucional. Año V. No 5. Lima, 1998, pp. 128-129.

14 “Los Jueces y Tribunales interpretan y aplican las leyes y toda norma con rango de ley y los reglamentos según los preceptos y principios constitucionales conforme a la interpretación de los mismos que resulte de las resoluciones dictadas por el Tribunal Constitucional en todo tipo de procesos".

15 Los juexces deben aplicar una norma cuya constitucionalidad haya sido confirmada por el Tribunal.

Los jueces suspenden la tramitación de los procesos de acción popular sustentados en normas respecto 
Víctor Malpartida Castillo - Tribunal Constitucional vs. Poder Judicial

(A propósito de un proceso competencial)

$48^{\circ 16}$ del mismo cuerpo normativo, se apunta en esa dirección. Entonces concluye: "De modo que el criterio de interpretación plasmado por el TC tendría que primar y no podría ser contradicho por las instancias del Poder Judicial. Con ello se evitaría la repetición de conflictos anteriormente suscitados, como cuando el TGC desestimó la inconstitucionalidad de alguna ley, no obstante lo cual -en acciones de amparo- algunos jueces o tribunales consideraron inconstitucional la misma norma y dispusieron inaplicarla al caso concreto".

Algo similar se dice actualmente para sustentar que el Tribunal Constitucional es el supremo intérprete de la Constitución. Así, Roger Rodríguez Santander advierte que "en contra de lo que algunos consideran la condición del TC como supremo intérprete de la Constitución no emana en última ratio de lo previsto por el artículo 1 de su Ley Orgánica, pues éste no es sino una plasmación a nivel legal de una previsión que emana de la propia sistemática constitucional.

“En efecto, si es a través de los procesos constitucionales(artículo 200) que se garantiza jurisdiccionalmente la fuerza normativa de la Constitución, y es(el TC) el encargado de dirimir en última(en el caso de las resoluciones denegatorias expedidas en los procesos de amparo, hábeas corpus, hábeas data y cumplimiento) o única instancia(procesos de inconstitucionalidad y competencial) tales procesos(artículo 203), resulta que al interior del Poder Jurisdiccional -llamado a proteger en definitiva(artículos 138 y 200 a 204) la supremacía normativa de la Constitución(artículos 38, 45 y 51)- el Tribunal Constitucional es su órgano supremo de protección (artículo 201) y, por ende, su supremo intérprete. No el único pero sí el supremo.

Es por ello que así lo tiene estipulado actualmente el artículo 1 de su Ley Orgánica -Ley No 28301- y el artículo 1 de (su) Reglamento Normativo. Y es por ello que el artículo VI del Título Preliminar del CPConst., luego de recordar el poder-deber de los jueces de inaplicar las leyes contrarias a la Constitución (artículo 138 de la Constitución) establece que no pueden dejar de aplicar una norma cuya constitucionalidad haya sido confirmada por este Colegiado en un proceso de inconstitucionalidad, y que deben interpretar y aplicar la leyes o toda norma con rango de ley y los reglamentos, según

de las cuales se ha planteado demanda de inconstitucionalidad ante el tribunal hasta que éste expida su resolución".

16 “cuando se promueva un conflicto constitucional con motivo de una disposición, resolución o acto cuya impugnación estuviese pendiente ante cualquier juez o tribunal, éste suspenderá el procedimiento hasta la resolución del Tribunal Constitucional". 
Víctor Malpartida Castillo - Tribunal Constitucional vs. Poder Judicial

(A propósito de un proceso competencial)

los preceptos y principios constitucionales, conforme a la interpretación de los mismos que resulte de las resoluciones dictadas por el Tribunal Constitucional. Éstas no son creaciones ex novo del legislador del CPConst., sino concretizaciones de una interpretación conjunta de los artículos 138, 201 y 203 de la Constitución"(Cfr. STC Exp. No 0030-2005-PI/TC, f.j. 46 y 47)"17.

Por su parte, Castillo Córdova habla de "posición preferente" del Tribunal Constitucional en relación al Poder Judicial. Así señala: "De entre estos dos encargados delajurisdicción constitucional enel Perú, el Tribunal Constitucional tiene una posición preferente. Ésta posición preferente se manifiesta no sólo en las mayores facultades que respecto de los jueces del Poder Judicial tiene asignado el referido tribunal (la declaración de inconstitucionalidad de las leyes y la resolución de los conflictos de competencias), sino que incluso en las competencias que comparte con los jueces del Poder Judicial, actúa como instancia última (procesos constitucionales de hábeas corpus, amparo y hábeas data). Esto hace del Tribunal Constitucional el supremo velador de la Constitución, y en la medida que velar por la Constitución exige interpretarla, se convierte también en el supremo intérprete de la Constitución (artículo 202 CP y artículo 1 Ley Orgánica del Tribunal Constitucional)"19.

Éste mismo autor señala en otro texto, que es particularmente conveniente "preguntarse si en el caso peruano se puede establecer alguna jerarquía entre los jueces ordinarios y el Tribunal Constitucional en tanto que Comisionados del poder constituyente. La respuesta a esta pregunta no es otra que afirmar una supremacía del citado Tribunal sobre los jueces ordinarios en lo que se refiere al control de la efectiva vigencia de la Constitución. Esto es así, no sólo porque la Constitución llama expresamente controlador de la Constitución

\footnotetext{
17 RODRÍGUEZ SANTANDER, Roger: «El precedente constitucional en el Perú. Entre el poder de la historia y la razón de los derechos». En: CARPIO MARCOS, Edgar y GRANDES CASTRO, Pedro (Coordinadores). Estudios del Precedente Constitucional. Lima: Editorial Palestra, 2007, pp. 58-59.

Ruíz Molleda opina al respecto: “En efecto, el carácter de supremo y definitivo intérprete es el resultado de una comprensión sistemática del conjunto de la Constitución, en especial de su artículo 201 (...); del artículo 202 y del artículo 204," (Ruíz MolledA, Juan Carlos. En defensa del Tribunal Constitucional: 10 razones jurídicas para resguardar sus potestades interpretativas. Lima: Justicia Viva. Instituto de Defensa Legal. Pontificia Universidad Católica del Perú - Facultad y Departamento Académico de Derecho, 2006, pp. 33). Es interesante también lo dicho por Herrera Vásquez: “(...)El TC es conceptualmente hablando, antes que nada un primus inter pares, un poder moderador o armonizador entre los poderes del Estado en relación a la Constitución. No está intrínsecamente hablando por encima de poder estatal alguno, pues lo contrario tentaría contra el Estado de Derecho contemporáneo(...)”. ( HERRERA VÁSQUEZ, Javier Ricardo. La difícil relación entre el Tribunal Constitucional y el Poder Judicial: ¿Guerra de las Cortes? Tesis presentada para optar el grado de Magíster en Derecho Constitucional. Escuela de Postgrado Pontificia Universidad Católica del Perú, Lima, enero 2009, pp. 25-26).

19 CAstillo CóRdova, Luís. «¿Activismo extralimitado del Tribunal Constitucional?. A propósito de un caso de vinculación de los jueces a la jurisprudencia del Tribunal Constitucional». En: Revista Jurídica del Perú. $\mathrm{N}^{\mathrm{0}} 77$, p. 25.
} 
Víctor Malpartida Castillo - Tribunal Constitucional vs. Poder Judicial

(A propósito de un proceso competencial)

sólo al Tribunal Constitucional; sino también -y principalmente-, por lo mayores poderes que para el cumplimiento del encargo tiene este respecto de los jueces ordinarios" 20 .

Asimismo, Santisteban de Noriega parte de considerar que la interpretación de la Constitución emanada del Tribunal Constitucional tiene carácter obligatorio para los jueces pues el mencionado papel contralor que le corresponde al Colegiado constitucional, "le da preeminencia intrínseca sobre otras interpretaciones a la luz de lo dispuesto por la Norma Fundamental y lo establecido en el último párrafo del artículo VI del Código Procesal Constitucional referido al valor de la doctrina constitucional". Concluye diciendo: "Esta superioridad que se opone al poder legiferante y subordina a todos los poderes públicos, precisamente para hacer prevalecer la supremacía de la Constitución y la vigencia efectiva de los derechos fundamentales, ¿es denigrante para el Poder Judicial? ¿Limita la independencia de los jueces y la autonomía institucional del poder que los representa? No lo creemos. En primer lugar, porque no hay otra manera de batallar jurídicamente por la jerarquía máxima e indiscutida de la Ley Suprema y los derechos fundamentales que estableciendo con claridad el papel contralor de la constitucionalidad que le corresponde al Tribunal. Pero más allá de ello, es preciso distinguir que tal supremacía abarca únicamente el campo constitucional, no supone que el Tribunal va a inmiscuirse en asuntos que no sean de su estricta competencia ni va a sustituir el criterio de los jueces en los asuntos especializados que se ventilan y deciden en instancia final en el seno del Poder Judicial" ${ }^{21}$.

Por otra parte, existen algunas posiciones críticas, como la de Aníbal Quiroga León. Señala que nada hay en nuestra Carta Constitucional que nos diga que la labor del Tribunal Constitucional subordina, hacia abajo, a la del Poder Judicial, o a la del Ministerio Público. El error se vuelve más evidente, aclara, cuando se observa la competencia del Poder Judicial en los procesos constitucionales: "Así, la última palabra en materia de hábeas corpus, amparo, hábeas data y acción de cumplimiento en el Tribunal Constitucional sólo estará reservada al Tribunal Constitucional frente a fallos adversos en sede

\footnotetext{
${ }^{20}$ CASTILlo CóRdOVA, Luís. «El carácter normativo fundamental de la Constitución peruana». En: Anuario de Derecho Constitucional Latinoamericano. Tomo I. Montevideo: Honrad Adenauer, 2006, p. 900.

21 SANTISTEBAN DE NorIEGA, Jorge. «Supremacía de la Constitución y de las interpretaciones del Tribunal Constitucional: límites y perspectivas a propósito de la sentencia recaída en el proceso competencial incoado por el Poder Ejecutivo(Mincetur)contra el Poder Judicial». En: ¿Guerra de las Cortes?. A propósito del proceso competencial entre el Poder Ejecutivo y el Poder Judicial. Coordinador: Domingo GARCía Belaunde. Palestra del Tribunal Constitucional 4. Cuadernos de Análisis y Crítica a la Jurisprudencia Constitucional. Editorial Palestra, Lima 2007, pp. 82-83.
} 
Víctor Malpartida Castillo - Tribunal Constitucional vs. Poder Judicial

(A propósito de un proceso competencial)

judicial, más no frente a los fallos estimativos del Órgano Jurisdiccional, los cuales no serán revisados ni por el Tribunal Constitucional ni por nadie en el Estado peruano. Luego, la interpretación que en los casos estimados haga el Poder Judicial también habrá de constituir jurisprudencia constitucional vinculante e intangible. ¿Cómo entonces se puede concluir que el Poder Judicial se halla subordinado al Tribunal Constitucional? ¿De qué parte, no tergiversada, de la Constitución surge ésta, por demás interesada, conclusión? Pues de ninguna, tanto más si, como ya se ha expresado, en el Perú el sistema de control constitucional es mixto, habiendo la Constitución provisto de una serie de instrumentos (de control orgánico y de la jurisdicción de la libertad) en sede judicial como en sede del Tribunal Constitucional, formando un todo, una distribución sistemática y no jerárquica. Nada hay, pues, en el texto ni en el espíritu de nuestra actual Carta Constitucional que avale semejante conclusión interpretativa..."22.

Todo lo anterior viene a colación ya que en la sentencia en comento, en los Fundamentos Jurídicos 51 y 52 se establecen unas consideraciones muy especiales en relación a la calidad del Tribunal Constitucional.

Así, en el Fundamento Jurídico 51 se señala que: "No se niega, como ya se señaló, que los jueces son independientes y autónomos en el ejercicio de la función jurisdiccional. Pero su actuación será constitucional sólo si respetan las relaciones entre los poderes del Estado y los órganos constitucionales. Más aún, en las relaciones entre el Tribunal Constitucional y el Poder Judicial, en materia de procesos constitucionales, existe una relación de grado inferior de éste con respecto a aquél, por hecho de que el Tribunal Constitucional es instancia final de fallo ante las resoluciones denegatorias del Poder Judicial en los procesos constitucionales de hábeas corpus, amparo, hábeas data, cumplimiento (artículo $200^{\circ}$, inciso 2 de la Constitución) e instancia única en el proceso de inconstitucionalidad y en el proceso competencial".

Lo anterior es reforzado en el Fundamento Jurídico 52 al señalarse: "Por eso mismo, si el constituyente, en nuestro ordenamiento, ha decidido consagrar al Tribunal Constitucional como guardián de los derechos fundamentales y órgano supremo "de control de la Constitución" (artículo 201), entonces, si bien no es el único intérprete, a él le corresponde decir la última palabra de

22 Quiroga LeÓN, Aníbal. «Análisis del conflicto de competencias del Poder Ejecutivo(Mincetur) con el Poder Judicial en el Tribunal Constitucional:¿una relación de jerarquía?». En: ¿Guerra de las Cortes?. A propósito del proceso competencial entre el Poder Ejecutivo y el Poder Judicial. Coordinador: Domingo García Belaunde. Palestra del Tribunal Constitucional 4. Cuadernos de Análisis y Crítica a la Jurisprudencia Constitucional. Editorial Palestra, Lima 2007, p. 127. 
Víctor Malpartida Castillo - Tribunal Constitucional vs. Poder Judicial

(A propósito de un proceso competencial)

lo que es o no constitucional, y ningún poder u órgano constitucional puede contradecirlo o desvincularse de sus decisiones, sino a costa de poner en cuestión nuestro sistema de justicia constitucional y el sistema democrático mismo".

Lo anterior es sumamente importante, pues es un argumento que está presente siempre en el actuar del Tribunal. Cuando en esta sentencia se señala expresamente que "en las relaciones entre el Tribunal Constitucional y el Poder Judicial, en materia de procesos constitucionales, existe una relación de grado inferior de éste con respecto a aquél", se culmina un razonamiento al respecto y una línea de desarrollo del propio Tribunal que unido a otros conceptos que ha establecido hacen que se explicite el control de la judicatura ordinaria.

Con la afirmación de la calidad jerárquica superior del Tribunal Constitucional, se desconoce -como hace ver Aníbal Quiroga León-, que existe en cuanto a procesos constitucionales una distribución sistemática y no jerárquica de competencias, es decir, como se ha explicado en acápites anteriores, la configuración de un sistema o modelo paralelo o dual de justicia constitucional, hace que tanto el Tribunal Constitucional como el Poder Judicial tengan ámbitos competenciales propios. Si bien, entonces, puede darse el caso que el Tribunal Constitucional corrija algunos pronunciamientos del Poder Judicial, también resulta claro constitucionalmente que éste último mantiene una competencia propia. Se puede concluir, por tanto, que constitucionalmente no hay ninguna razón o fundamento que avale lo que tan entusiastamente se afirma en la sentencia en análisis.

Por ello, es precisamente esa distribución sistemática y no jerárquica de competencias, la que desconocen Sáenz Dávalos, Carpio Marcos y Rodríguez Santander, en el Informe al Pleno del Tribunal Constitucional sobre el proyecto de ley que modifica algunas de sus funciones (Proyecto de Ley $\mathrm{N}^{\circ}$ $14321 / 2005-C R)^{23}$. Así, los autores parten de la afirmación que entre órganos constitucionales no existe una relación de jerarquía. No obstante ello, "al interior del Poder Jurisdiccional sí existe una jerarquía constitucional, pues aún cuando todo juez se encuentra obligado a preferir la Constitución frente a las leyes (artículo $138^{\circ}$ de la Constitución) y, consecuentemente, facultado a interpretarla, el Poder Constituyente ha establecido que el contralor, por antonomasia, de la constitucionalidad es el TC (artículo $201^{\circ}$ de la

\footnotetext{
${ }^{23}$ SÁEnz DÁvalos, Luís; CARPIO MARCos, Edgar; y Rodríguez SANTANDER, Roger. «Informe al Pleno del Tribunal Constitucional sobre el proyecto de ley que modifica algunas de sus funciones». En: Justicia Constitucional. Revista de Jurisprudencia y Doctrina. Año II, No 4, julio-diciembre, Lima 2006, p. 320-321.
} 
Víctor Malpartida Castillo - Tribunal Constitucional vs. Poder Judicial

(A propósito de un proceso competencial)

Constitución)". Lo nuevo de éste planteamiento es que se especifica que la "jerarquía constitucional" es al "interior del Poder Jurisdiccional", aspecto no señalado expresamente en la sentencia en el Exp. 006-2006-PC/TC. Sin embargo, como ya se dijo, se mantiene el criterio de la relación de jerarquía entre el Tribunal Constitucional y el Poder Judicial, en atención a una consideración errónea de observar una jerarquía de competencias donde en verdad existe una distribución sistemática de las mismas, como bien aprecia Aníbal Quiroga León. Todo los demás argumentos esgrimidos caen al caer el sustento anterior.

Pensamos que debe distinguirse entre ser el Tribunal Constitucional el "supremo intérprete de la Constitución", con una "superioridad jerárquica" en relación al Poder Judicial. Si bien lo primero ha sido establecido en el artículo $1^{\circ}$ de la Ley Orgánica del Tribunal Constitucional -mas no en la Constitución, ni en el Código Procesal Constitucional- no puede aceptarse que el Tribunal devenga en jerárquicamente superior que el Poder judicial, ya que ambas instituciones constitucionalmente mantienen sus ámbitos interactuando.

Lo anterior debe ser corroborado, en tanto se tiene en cuenta que en un Estado Constitucional, no puede hablarse de jerarquías entre los poderes constituidos, como son el Poder judicial y el Tribunal Constitucional.

\subsubsection{Precedentes constitucionales vinculantes}

Se señala que hacia el siglo XIV ya se citan los precedentes en el derecho inglés, sin embargo -como recalca Juan Monroy Gálvez- carecían del efecto vinculante que se le reconoce ahora. Victoria Iturralde -citada por el procesalista peruano- señala que "el significado que hoy en día tiene el precedente es distinto al que tuvo en sus orígenes. Entonces las decisiones de los tribunales eran consideradas expresiones de opiniones acerca del derecho cuyo peso dependía del juez o jueces que la pronunciaban, pero no obligaban a los jueces a seguirlas. Aunque los casos se decidían por referencia a decisiones anteriores, éstas no eran prácticas que se veían como obligatorias, ni como un conjunto que formaba un sistema de leyes. La cita de precedentes era un poderoso instrumento retórico o argumentativo ya desde la mitad del siglo XIV, pero los juristas de este periodo tenían claro que "ningún precedente es tan persuasivo como la razón" 24 .

${ }^{24}$ MONROY GÁLVEZ, Juan. «Apuntes sobre la doctrina del precedente y su influencia en el civil law». En: Hechos de la justicia. $\mathrm{N}^{\circ}$ 4, septiembre-diciembre, 2006. 
Luego, de manera creciente se iba a acentuar la práctica de los jueces de resolver los casos de la forma como se habían resueltos casos análogos. A esta práctica se le incorporaron dos rasgos. De un lado, la importancia social del fallo, vale decir, su contenido didáctico y, asimismo, de otra parte, empezó a adquirir significación la calidad del tribunal que había expedido la decisión a ser seguida. Para Monroy Gálvez, "este es el punto de partida histórico de lo que ahora se da en llamar stare decisis o doctrina del precedente" ${ }^{25}$.

Por su parte, Francesca Moretti citando lo resuelto en el caso Mirehouse v. Rennel 1833, por el Juez Park, señala que se resume sustancialmente los elementos que componen la doctrine of judicial precedent: "Nuestro sistema del common law consiste en aplicar a los nuevos supuestos las reglas de derecho que nosotros, jueces, derivamos de los principios jurídicos y de los precedentes judiciales; $y$ con el fin de garantizar la uniformidad, la coherencia y la certeza del derecho debemos aplicar estas reglas, con tal que no sean claramente ilógicas o estén fuera de lugar, a todos los casos iguales que se presenten; y no tenemos posibilidad alguna de desatenderlas o de rechazar su aplicación analógica prefiriendo otras no consagradas nunca judicialmente, sólo porque consideremos que tales reglas no sean tan oportunas y ajustadas como deseáramos. Considero de extrema importancia mantener este canon absolutamente firme, no sólo para la resolución del caso en cuestión, sino sobre todo por el interés superior del derecho como sistema científico" ${ }^{26}$.

De similar manera, Magaloni ${ }^{27}$ parte de resaltar que en el sistema jurídico norteamericano los tribunales desempeñan dos funciones. La primera, es la de resolver disputas jurídicas, esto es, administrar justicia ante casos concretos. La segunda función de los tribunales es la de proveer a la sociedad de reglas jurídicas. Magaloni señala que "el principio de stare decisis hace que las decisiones judiciales que resuelvan alguna cuestión de derecho deban ser consideradas como parámetro normativo en la resolución de casos similares que se presenten con posterioridad. Esta facultad para crear derecho en forma casuística se denomina función institucional".

Si tuviéramos que mostrar una definición operativa de la doctrina del precedente se tendría: "cuando en un sistema jurídico se conforma un conjunto de reglas y principios -que reciben el nombre de case law-que

\footnotetext{
25 Ibid., p. 11.

${ }^{26}$ MoRETTI, Francesca: «El precedente judicial en el sistema inglés». En: GALGANO, Francesco: Atlas de Derecho Privado Comparado. Madrid: Fundación Cultural del Notariado, 2000, p. 29.

27 Magaloni Kerpel, Ana Laura. El precedente constitucional en el sistema judicial norteamericano. Madrid: Mc Graw Hill, 2001, pp. 30-31.
} 
Víctor Malpartida Castillo - Tribunal Constitucional vs. Poder Judicial

(A propósito de un proceso competencial)

son extraídos de las decisiones que toman los jueces en un contexto histórico determinado y los cuales vinculan -sea de manera persuasiva u obligatoria- a otros jueces del mismo sistema en casos en donde se presente analogía con el caso ya resuelto" 28 .

Ahora bien, un aspecto importante en relación con los precedentes es su clasificación. Así, atendiendo a su vinculación e influencia futura se tiene que pueden darse los precedentes obligatorios y aquellos persuasivos.

Los obligatorios "son precedentes que los jueces deben de seguir, sea que lo aprueben o no. La fórmula que determina la vinculación es como sigue: Una proposición afirmada en el caso A es obligatoria en el caso B si: 1. Se trata de una fundamentación jurídica; 2. Esta proposición tiene la calidad o es parte de la ratio decidendi del caso A; 3 . El juez o tribunal que estableció el caso A tiene vinculación de obligatoriedad (es decir, hay en el plano jurídico una relación vertical) con el juez o tribunal que está por decidir el caso B; y 4. No existe diferencia relevante que permita considerar que el caso A pueda ser declarado un caso "distinguible" "29.

De otra parte, los persuasivos serán aquellos que no teniendo la categoría de los anteriores, poseen esa calidad de convencimiento o persuasión que le da la autoridad correspondiente para ser invocados en un momento determinado.

Lo importante de este criterio clasificatorio es representar a una tendencia: "procurar que la eficacia vinculante del precedente no sea absoluta ni rígida por un lado y, por otro, permitir que el juez vinculado pueda apartarse del precedente cuando hayan razones de considerable importancia que así lo determinen" 30 .

Lo anterior tiene mucha relación con preguntarse sobre si es posible apartarse del precedente vinculante. Como se encarga de explicar Monroy Gálvez, se guarda un equilibrio entre la regla que es el seguimiento obligatorio del precedente y la posibilidad del apartamiento del mismo por razones de utilidad social o pública, llegando a una flexilbilidad acentuada: "Sea por considerar al common law como un organismo vivo que crece y evoluciona conforme lo hace la sociedad -por lo que se debe permitir su desarrollo aunque dentro de límites en los cuales se pueda concretar esta capacidad de maniobra-, sea por considerar que siendo los precedentes sólo la aplicación

\footnotetext{
${ }^{28}$ MONROY GÁLVEZ, Juan. «Apuntes sobre la doctrina del precedente y su influencia en el civil law». En: Hechos de la justicia. $\mathrm{N}^{\circ}$ 4, septiembre-diciembre 2006, p. 11.

29 Ibid., p. 17.

30 Ibid., p. 17.
} 
Víctor Malpartida Castillo - Tribunal Constitucional vs. Poder Judicial

(A propósito de un proceso competencial)

de principios que subyacen en el espíritu del pueblo, cuando éste deviene en contrario al principio, debe dejar de ser obligatorio, lo trascendente es que la evolución contemporánea de la doctrina del precedente está íntimamente ligada las posibilidades técnicas de que produzcan apartamientos de los ratios sin afectar sustancialmente el stare decisis" 3132.

Esa flexibilidad, al parecer, es una característica muy marcada de la doctrina del precedente. Matttei explica que una multitud de factores determinan el carácter más o menos rígido de la regla del stare decisis en el mundo contemporáneo del common law. Así, señala la unidad o pluralidad de las pirámides judiciales, con su relativa mayor o menor posibilidad de precedentes conflictivos; la presencia o la ausencia de constituciones escritas que incorporan o hacen inmediatamente actuables reglas jurídicas de amplio contenido y de notable alcance político; el nivel de madurez de la cultura jurídica nacional, con su correspondiente impacto crítico en las decisiones de los jueces a las que hay que atenerse; las características de los repertorios jurisprudenciales, y la cantidad de decisiones publicadas. Señala Mattei que en los Estados Unidos todos los factores contribuyen a hacer elástica la regla de stare decisis ya que existen más de cincuenta pirámides distintas, teóricamente independientes; la Constitución induce a una decisión en clave de public policy; la cultura académica es hasta demasiado crítica: la cantidad de decisiones publicadas ha superado desde hace tiempo un nivel crítico, de modo que -como manifiesta Mattei- "para todo se puede encontrar una cita favorable y contraria". Ahora bien, en cuanto a los otros sistemas del common law Mattei señala que se sitúan en posiciones intermedias entre los ingleses y los americanos, en tanto el sistema inglés es más rígido que el norteamericano ${ }^{33}$.

La razón que nos ocupemos del precedente vinculante es no solo por el hecho que en la sentencia en el Exp. 006-2006-PC/TC se haya hecho mención, sino que esta figura a partir del Código Procesal Constitucional se introdujo en el artículo VII del Título Preliminar de la manera siguiente: "Las sentencias del Tribunal Constitucional que adquieren la autoridad de

\footnotetext{
31 Ibid., p. 20.

32 López Guerra señala: “En los países pertenecientes al sistema jurídico del common law el principio stare decisis(de stare decisis et non quieta movere)se configura como clave para conseguir la realización del principio de seguridad jurídica, superando posibles divergencias entre las diversas instancias jurisdiccionales, y haciendo posible la introducción de criterios comunes a todas ellas(...)"(LÓPEZ GUERRA, Luís. «El Tribunal Constitucional y el principio "stare decisis"». En: AA. VV. El Tribunal Constitucional. Madrid: Instituto de Estudios Fiscales, 1981, pp. 1439, 1440).

${ }_{33}$ MatteI, Ugo: «Stare decisis en los Estados Unidos». En: Galgano, Francesco. Atlas de Derecho Privado Comparado. Madrid: Fundación Cultural del Notariado, 2000, p. 50.
} 
Víctor Malpartida Castillo - Tribunal Constitucional vs. Poder Judicial

(A propósito de un proceso competencial)

cosa juzgada constituyen precedente vinculante cuando así lo exprese la sentencia, precisando el extremo de su efecto normativo. Cuando el Tribunal Constitucional resuelva apartándose del precedente, debe expresar los fundamentos de hecho y de derecho que sustentan la sentencia y las razones por las cuales se aparta del precedente".

El Tribunal Constitucional ha señalado en la STC 0024-2003-AI/TC, que "el precedente constitucional vinculante es aquella regla jurídica expuesta en un caso particular y concreto que el Tribunal Constitucional decide establecer como regla general; $\mathrm{y}$, que por ende, deviene en parámetro normativo para la resolución de futuros procesos de naturaleza homóloga". Seguidamente añade a lo dicho que: "El precedente constitucional tiene por su condición de tal, efectos similares a una ley. Es decir, la regla general externalizada como precedente a partir de un caso concreto se convierte en una regla preceptiva común que alcanza a todos los justiciables y que es oponible frente a los poderes públicos".

En la misma sentencia, el Tribunal se refiere en cuanto a la naturaleza del precedente: "La naturaleza del precedente tiene una connotación binaria. Por un lado, aparece como una herramienta técnica que facilita la ordenación y coherencia de la jurisprudencia; $y$, por otro, expone el poder normativo del Tribunal Constitucional dentro del marco de la Constitución, el Código Procesal Constitucional y la Ley Orgánica del Tribunal Constitucional".

De otra parte, se debe establecer las diferencias existentes entre el precedente constitucional vinculante y la jurisprudencia constitucional vinculante. Esta última es incluida en el artículo VI del Título Preliminar del Código Procesal Constitucional: "Los jueces interpretan y aplican las leyes o toda norma con rango de ley y los reglamentos según los preceptos y principios constitucionales, conforme a la interpretación de los mismos que resulte de las resoluciones dictadas por el Tribunal Constitucional".

Asimismo, en la STC 3741-2005-AA/TC, el Tribunal ha establecido que: "Las sentencias del Tribunal Constitucional, dado que constituyen la interpretación de la Constitución del máximo tribunal jurisdiccional del país, se estatuyen como fuente de derecho y vinculan a todos los poderes del Estado(...)La jurisprudencia constituye, por tanto, la doctrina que desarrolla el Tribunal en los distintos ámbitos del derecho, a consecuencia de su labor frente a cada caso que va resolviendo".

En esta misma sentencia citada se establece la diferencia entre el precedente constitucional vinculante y la jurisprudencia constitucional vinculante: "(...) si bien tanto la jurisprudencia como el precedente constitucional tienen en 
común la característica de su efecto vinculante, en el sentido de que ninguna autoridad, funcionario o particular puede resistirse a su cumplimiento obligatorio, el Tribunal, a través del precedente constitucional, ejerce un poder normativo general, extrayendo una norma a partir de un caso concreto".

Igualmente, es necesario establecer la diferencia entre el precedente judicial y el precedente constitucional vinculante. En la STC 3741-2005-AA/TC, se señala: “(...)el precedente judicial en el sistema del Common Law se ha desarrollado como precedente vinculante en sentido vertical; es decir, aplicable desde la Corte Suprema(para el caso norteamericano) hacia las cortes y juzgados inferiores de todo el sistema judicial. O sea, el efecto vinculante se establece aquí básicamente respecto de los jueces(...)El precedente constitucional en nuestro sistema tiene efectos más generales.(...)el efecto sobre todos los poderes públicos de las sentencias del Tribunal Constitucional. Esto significa que el precedente vinculante emitido por un Tribunal Constitucional con estas características tiene, prima facie, los mismos efectos de una ley. Es decir, que la regla que el Tribunal externaliza como precedente a partir de un caso concreto, es una regla para todos y frente a todos los poderes públicos(...)".

Cabe preguntarnos sobre si lo correspondiente al precedente constitucional vinculante tiene alguna peculiaridad que lo singulariza del referente anglosajón. Esa peculiaridad puede verse en relación al cambio de precedente vinculante. Así, la segunda parte del artículo VII del Título Preliminar del Código Procesal Constitucional ha previsto de manera expresa la posibilidad de que el Tribunal Constitucional varíe su propio precedente vinculante, añadiendo César Landa, que el legislador "ha reservado para el propio TC la competencia exclusiva del cambio de su precedente(...)Claro está que ello no impide que el juez dejando salvada su interpretación particular falle de conformidad con el precedente vinculante por mandato expreso de la ley; pero, sí requiere de un juez leal con la interpretación realizada por el TC, más aún cuando el incumplimiento de la misma ha dado lugar a que el órgano de control administrativo de los jueces del Poder Judicial, la Oficina de Control de la Magistratura(OCMA), haya establecido mediante resolución que su incumplimiento es mérito de responsabilidad administrativa" ${ }^{\prime 34}$.

Con esto entonces, podemos concluir que a diferencia del precedente vinculante del sistema anglosajón en el cual prima la flexibilidad e impera la elasticidad -sobre todo en el sistema norteamericano más que en el inglésaquí se ha plasmado un sistema particular, rígido, en el que aparte de reservar

\footnotetext{
${ }^{34}$ LANDA, César: «Los precedentes constitucionales». En: Justicia Constitucional. Revista de Jurisprudencia y Doctrina. Año III, No 5, enero-junio, Lima 2007, p. 57.
} 
Víctor Malpartida Castillo - Tribunal Constitucional vs. Poder Judicial

(A propósito de un proceso competencial)

el cambio en el precedente solo al Tribunal Constitucional, el juez no tiene posibilidad de fallar distinto que el precedente, ya que, como bien lo apunta Landa, es motivo de responsabilidad administrativa.

$\mathrm{Al}$ respecto Roger Rodríguez Santander ${ }^{35}$, de manera muy didáctica señala que el sistema de precedente constitucional vinculante establecido en el Perú puede ser etiquetado como "entre lo anglosajón y lo continental". Señala: “(...)la principal diferencia entre el precedente constitucional previsto en el art. VII CPConst. y el precedente del common law(además del hecho mismo de encontrarse regulado), sea que mientras en éste es al juez posterior a quien corresponde determinar la ratio decidendi que servirá de norma aplicable para los futuros casos análogos, en el caso peruano, la regla es determinada por el propio $\mathrm{TC}$, pues conforme señala el referido artículo, es a éste al que corresponde precisar "el extremo de su efecto normativo"(...)mientras que en el common law, el juez posterior tiene abierto un margen para determinar las consideraciones de Derecho y los hechos relevantes en la configuración del precedente, en nuestro sistema dicha determinación viene realizada por el propio TC.".

Para Rodríguez Santander "se presenta una fusión entre la tradición anglosajona del precedente y determinada forma de concebir el Derecho en la tradición continental. Los signos anglosajones se observan, fundamentalmente, en la intención de dotar de fuerza vinculante plena a los precedentes constitucionales del tribunal de máxima jerarquía en la materia, asegurando su entendimiento como verdadera fuente creadora de Derecho. Mientras que los caracteres del civil law se evidencian en la regulación del instituto como una fuerza impositiva que se proyecta con la misma rigidez con la que lo hace el Derecho legislado"36 37.

Se cercena esa flexibilidad o elasticidad del sistema de precedentes anglosajón más aún cuando en dicho sistema se está acentuando esa flexibilidad y

\footnotetext{
35 Rodríguez SANTANDER, Roger. Op. Cit., pp. 62-63.

36 Ibid., p. 63. Una opinión matizada sobre la obligatoriedad del precedente vinculante se encuentra en Javier Antonio Adrián Coripuna: "El cambio de la orientación jurisprudencial (overruling) contenida en un precedente vinculante del Tribunal Constitucional solo puede ser realizado por el mismo Tribunal. En otros términos, el precedente sólo lo puede cambiar el órgano que lo expidió. Ciertamente, los jueces de nivel inferior no pueden cambiar el precedente, aunque si, excepcionalmente, podrían apartarse del mismo, justificando su decisión, con lo que motivarían que el TC se pronuncie nuevamente cambiando, si así lo estima, el precedente instaurado(...)el juez de instancia inferior puede apartarse del precedente(nunca cambiarlo pues esto solo lo puede hacer el Tribunal Constitucional), mediante una motivación específica adicional de por qué se hace tal alejamiento, de modo tal que se ponga en conocimiento del Alto Tribunal la exigencia de que el precedente debe cambiar o en todo caso motivar en este una justificación que, manteniendo el precedente, responda al nuevo contexto planteado(...)".(ADRIÁN CORIPUNA, Javier Antonio: «La jurisprudencia vinculante de los altos tribunales como límite al principio de independencia judicial». En: CARPIO MaRCos, Edgar y GRANDEZ CASTRO, Pedro(Coordinadores). Estudios del Precedente Constitucional. Lima: Editorial Palestra, 2007, p. 132).
} 
Víctor Malpartida Castillo - Tribunal Constitucional vs. Poder Judicial

(A propósito de un proceso competencial)

elasticidad actualmente. Por ello, no nos parece real que -como manifiesta Rodríguez Santander- al no ser un precedente una ley, "no enerva la posibilidad de que los jueces evalúen razonablemente y comparen los elementos jurídicos y fácticos que fueron considerados relevantes por el TC y que traslucen en el precedente establecido, con los que caracterizan su caso, de forma tal que identificado un componente significativo que los distinga, resuelvan su causa siguiendo una línea diferente".

Y no nos parece real pues, como ocurrió en el Exp. 0525-2011-PA/TC, se establece que toda resolución judicial que vaya en contra del precedente vinculante era nula por contravenirlo en forma manifiesta, recordando que todos los jueces "tienen la obligación de acatar el precedente vinculante mencionado a fin de no vulnerar los derechos constitucionales de los pensionistas y preservar el principio de seguridad jurídica."(Fundamento Jurídico 5), desautorizando lo señalado por la Primera Sala Civil de la Corte Superior de Justicia de Lima -integrada por los vocales superiores Romero Díaz, Emilia Bustamante Oyague y Rómulo Torres Ventocilla-, quienes resolvieron incrementar el monto económico fijado para el reclamo de los pensionistas que presentaban demandas de amparo ante el Poder Judicial estableciéndolo en 600 nuevos soles, al considerar que el monto fijado en el precedente vinculante de la STC 1417-2005-AA/TC, había quedado desfasado porque su fecha era de 12 de julio de 2005.

Por todo lo anterior, nos parecen atinadas las críticas que se efectúan a esta forma de asumir los precedentes constitucionales vinculantes. Así, por ejemplo, Monroy Gálvez señala: "Algunos entusiasmos frente a algunas aparentes novedades y un desconocimiento de sus aspectos técnicos son los causantes de esta situación increíble que vivimos ahora en donde un apartamiento de un precedente del Tribunal Constitucional provoca la nulidad ipso iure de la decisión tomada. Esta es una dictadura jurídica, reitero por necesario, inexistente en el mundo. En este tema, entonces, somos el único olmo que da peras" ${ }^{\prime 38}$.

\footnotetext{
37 Grández Castro relaciona el modelo de precedente adoptado en nuestro país y la concepción de juez que subyace a dicho modelo: "Tal como ha sido presentado hasta aquí, el precedente peruano se ha apartado de modo radical de esta tradición del common law. Aquí la regla precedente viene estatuida en el propio fallo y con precisión de una regla que no admita confusiones. Quizá la explicación a esto haya que buscarla en la permanente falta de confianza hacia la capacidad de juicio de los jueces del Poder Judicial".(GRÁNDEZ CASTRO, Pedro: «Las "peculiaridades" del precedente constitucional en el Perú». En: CARPIO MARCOS, Edgar y GRANDES CASTRO, Pedro(Coordinadores). Estudios del Precedente Constitucional. Lima: Editorial Palestra, 2007, pp. 99-100).

38 "Fundamentos, problemas y posibilidades del precedente constitucional vinculante en el Perú. Entrevista a Juan Monroy Gálvez y Aníbal Torres Vásquez", en: JUS Constitucional No 1 Editorial Grijley, enero 2008, p. 120 ,
} 
Víctor Malpartida Castillo - Tribunal Constitucional vs. Poder Judicial

(A propósito de un proceso competencial)

Similarmente Domingo García Belaunde señala que con el precedente vinculante "han querido imponer una dictadura virtual sobre el resto de los operadores jurídicos", añadiendo: "Si bien es cierto que el concepto que ha acogido nuestra dogmática ha permitido estos excesos y hay necesidad de matizarlo, o mejor aún, de reformularlo" ${ }^{39}$.

Pensamos asimismo que no se debe renunciar a la mencionada flexibilidad, en tanto se arguye que para un país como el nuestro no había otra posibilidad de plantearlo como se hizo ${ }^{40}$.

\subsubsection{Cosa juzgada constitucional}

El procesalista italiano Giuseppe Chiovenda señala que "el bien de la vida que el actor ha deducido en juicio (res in iudicium deducta) con la afirmación de que una voluntad concreta de ley lo garantice en su favor o lo niegue al demandado, después que ha sido reconocido o desconocido por el juez con la sentencia estimatorio o desestimatoria de la demanda, se convierte en cosa juzgada (res iudicata)".

La res iudicata no es otra cosa para los romanos - aclara el maestro a quien seguimos en esta parte ${ }^{41}$ - que la res in iudicium deducida después de que ha sido iudicata: res iudicata dicitur quae finem controversiarum pronunciatione iudicis accipit, quod vel comdenatione vel absolutione contingit. Podemos igualmente decir - aclara el jurista - que la cosa juzgada no es nada más que el bien juzgado, el bien reconocido o desconocido por el juez $(\ldots)^{\prime \prime} 4243$.

39 García Belaunde, Domingo: Op. Cit., p. 32.

40 Rodríguez señala: “¿Había alguna otra manera de tentar que la doctrina del precedente tenga una verdadera presencia en nuestro medio? Con sinceridad no lo sabemos. Pero lo que sí sabemos es que ello no se iba a dar como consecuencia de un milagroso cambio en la concepción del Derecho por parte de nuestros jueces o legisladores. Por ello, es probable que los creadores del CPConst. hayan acertado". En: RODRíGUEZ SANTANDER, Roger. Op. Cit., p. 63.

41 ChIovenda, Giuseppi. Instituciones de Derecho Procesal Civil. Volumen I. Madrid: Editorial Revista de Derecho Privado, 1954, p. 432 y ss.

42 De manera muy sencilla Jordi Nieva explica el fundamento de la cosa juzgada: "El principio básico del que parte el concepto de cosa juzgada es el siguiente: Los juicios sólo deben realizarse una única vez.(...) La razón de ello es muy evidente, y puede resumirse de este modo: la seguridad jurídica requiere que sobre cada asunto solamente pueda decidirse una única vez.(...)"(NiEVA FERROLL, Jordi. La Cosa Juzgada. Barecelona: Editorial Atelier, 2006, pp. 119-120).

43 Ana María Arrarte, al respecto dice que para entender el sustento de la autoridad de la cosa juzgada, se debe partir de un tema central: el principio de preclusión, constituyendo el núcleo de toda racionalidad de ese instituto. (ARRARTE ARISNABARRETA, Ana María. "Apuntes sobre los alcances de la autoridad de la cosa juzgada en el proceso civil peruano». En: AA. VV.: Doctrina Contemporánea. Trujillo Editora Normas Legales, 2003, p.458). 
Víctor Malpartida Castillo - Tribunal Constitucional vs. Poder Judicial

(A propósito de un proceso competencial)

Por otra parte, Juan Monroy Gálvez ${ }^{44}$, destaca que si el fin abstracto del proceso es la paz social en justicia, tal encargo solo va a poder ser cumplido cuando las decisiones judiciales no admitan ningún cuestionamiento, es decir, cuando los obligados con ellas las cumplan, sea espontáneamente o a través del uso de la facultad coercitiva del Estado.

Para que los fines del proceso se concreten - advierte Monroy - es indispensable que la decisión final que se obtenga en este sea de exigencia inexorable. Esta calidad de indiscutibilidad y de certeza en su contenido es una autoridad intrínseca que acompaña a las resoluciones judiciales y recibe el nombre de cosa juzgada -concluye-. Asimismo, Susana Castañeda ${ }^{45}$ precisa que cuando se señala que una resolución ha adquirido la calidad de cosa juzgada, equivale a decir a que no puede ser modificada ni que el proceso sea reabierto ${ }^{46}$.

Los primeros antecedentes de la cosa juzgada en el ámbito nacional a nivel constitucional se remontan -como aclara Castañeda- a las Constituciones de 1828(artículo 161), 1834(artículo 127), 1839(artículo 129), 1856(artículo 130), 1860(artículo 129), 1867(artículo 127), 1920(artículo 155), y de 1933(artículo 228). Todos ellos establecen "la prohibición de revivir procesos fenecidos".

Castañeda precisa que en la Constitución de 1979, el artículo 2 inciso 20 consagró el derecho a la libertad y seguridad personales, estableciendo en el literal 1l) que: "La amnistía, el indulto, los sobreseimientos definitivos y las prescripciones producen los efectos de cosa juzgada". Además en el inciso 11 del artículo 233, estableció como una garantía de la administración de justicia la prohibición de revivir procesos fenecidos, no pudiendo nadie ser juzgado nuevamente por hechos por los cuales haya sido absuelto o condenado por sentencia firme.

La actual Constitución -siguiendo a Castañeda- regula la cosa juzgada en el artículo 139 incisos 2 y 13 como un principio y derecho de la función

\footnotetext{
44 Monroy GÁlveZ, Juan. Introducción al proceso civil. Tomo I. Santa Fe de Bogotá: Editorial Temis, 1996, pp. 86-87.

45 Castañeda Otsu, Susana. «Cosa Juzgada». En: AA. VV. La Constitución Comentada. Tomo II. Lima: Gaceta Jurídica, 2006, pp. 568 y ss.

${ }^{46}$ Hitters explica la exigencia de la cosa juzgada: "(...como bien puntualizaba Couture, la cosa juzgada es una exigencia política y no propiamente jurídica, no es de razón natural, sino una necesidad práctica.

De lo expresado se desprende una conclusión anticipada: la institución aludida si bien es una pieza fundamental de la maquinaria judicial; su estabilidad se apontoca en el principio de seguridad, y en determinadas circunstancias razones de equidad admiten su alteración(...)En suma, el principio de inmutabilidad de los decisorios firmes está previsto por razones de política jurídica y esas mismas fundamentaciones pueden en determinadas y excepcionalísimas ocasiones aconsejar la necesidad de variar el criterio" (HitTERS, Juan Carlos. «Revisión de la cosa juzgada. Su estado actual». En: Revista Peruana de Derecho Procesal IV. Lima, 2001, p. 93).
} 
Víctor Malpartida Castillo - Tribunal Constitucional vs. Poder Judicial

(A propósito de un proceso competencial)

jurisdiccional. Así, en el inciso 2 se deja establecido que ninguna autoridad puede dejar sin efecto resoluciones que han pasado en autoridad de cosa juzgada; y en el inciso 13 se establece la prohibición de revivir procesos fenecidos mediante una resolución ejecutoriada, señalándose en éste último además que como supuestos que surten los efectos de la cosa juzgada a la amnistía, el indulto, el sobreseimiento definitivo y la prescripción.

Ahora bien, el Tribunal Constitucional en la STC 006-2006-PC/TC plantea el concepto de "cosa juzgada constitucional", ante la argumentación de los afectados sobre la declaración de fundada la demanda en cuanto a la violentación de la cosa juzgada reconocida en el artículo $139^{\circ}$ inciso 2 de la Constitución.

El Tribunal plantea que lo que la Constitución garantiza en el numeral señalado es la "cosa juzgada constitucional", "la que se configura con aquella sentencia que se pronuncia sobre el fondo de la controversia jurídica, de conformidad con el orden objetivo de valores, con los principios constitucionales y con los derechos fundamentales, y de acuerdo con la Interpretación que haya realizado el Tribunal Constitucional de las leyes, o de toda norma con rango de ley, o de los reglamentos y de sus precedentes vinculantes, como lo prescriben los artículos VI y VII del Título Preliminar del Código Procesal Constitucional, respectivamente. Solo de esa manera un ordenamiento constitucional puede garantizar a la ciudadanía la certeza jurídica y la predictibilidad de las decisiones jurisdiccionales". (Fundamento Jurídico 70).

De este concepto de "cosa juzgada constitucional", a lo que tradicionalmente se tiene como cosa juzgada, se añade -y es lo resaltante- que tendrá la calidad de tal aquella sentencia de acuerdo con la doctrina jurisprudencial y los precedentes vinculantes que devienen del Tribunal -los que al integrarse "en el sistema de fuentes de nuestro sistema jurídico"(Fundamento Jurídico 69)-, se convierten en parámetros de validez y legitimidad constitucionales. En pocas palabras, si lo que se resuelve, particularmente, no va de acuerdo con lo establecido por el Tribunal Constitucional no es válido y no será pasible de adquirir la calidad de cosa juzgada constitucional.

Con lo anterior se cierra el círculo de la influencia y control del Tribunal Constitucional sobre el Poder Judicial y lo dice al final de la cita: "Sólo de esa manera un ordenamiento constitucional puede garantizar a la ciudadanía la certeza jurídica y la predictibilidad de las decisiones jurisdiccionales". Lo que no dice el Tribunal es que cuando se refiere a decisiones jurisdiccionales se tiene en mente "sus decisiones jurisdiccionales", interesando solo lo que ellos determinan como conveniente. Finalmente ellos -el Tribunal- son los que pueden establecer que es verdad y que no lo es. 
Víctor Malpartida Castillo - Tribunal Constitucional vs. Poder Judicial

(A propósito de un proceso competencial)

Por otra parte, es importante conocer de dónde deviene el concepto de "cosa juzgada constitucional". Al respecto, Néstor Pedro Sagüés ${ }^{47}$ es claro en conceptuarla, catalogándola como uno de los asuntos más atractivos del derecho procesal constitucional. Se entiende, dice "el efecto que pueda tener una sentencia dictada en materia constitucional, mediante un proceso constitucional por un órgano jurisdiccional de la magistratura constitucional".

De lo anteriormente desarrollado se tiene que por los elementos que encierra el concepto de "cosa juzgada constitucional" (un fallo proveniente de la magistratura constitucional jurisdiccional; pronunciamiento sea emitido en el curso de un proceso y un procedimiento constitucional destinado a tutelar la supremacía de la Constitución, y respetuoso de las exigencias procesales de ella; $y$, que aborda temas constitucionales), entonces estaría preferentemente ligado a los procesos de inconstitucionalidad, cuyas sentencias tendrían tal calidad, lo que entonces, se distanciaría de lo que ha establecido el Tribunal Constitucional peruano, el cual alude al cumplimiento de ciertos requisitos, entre ellos, y el más importante para el órgano de control constitucional nacional, la conformidad con la interpretación que haya realizado el Tribunal Constitucional de las leyes, o de toda norma con rango de ley, o de los reglamentos y de sus precedentes vinculantes, como lo prescriben los artículos VI y VII del Título Preliminar del Código Procesal Constitucional.

Uno de los aspectos que se debe abordar, es la relación entre cosa juzgada e independencia judicial. Así, resulta sintomático que el inciso 2 del artículo $139^{\circ}$ de la Constitución peruana vigente se establezca a la independencia del Poder Judicial en el ejercicio de su función jurisdiccional como principio, y en el mismo texto más adelante la referencia a la cosa juzgada ${ }^{48}$.

Entonces, se establece una relación directa entre cosa juzgada e independencia judicial, ya que la primera es parte de la esencia de la función jurisdiccional y si la cosa juzgada emanada de los procesos resueltos finalmente por el Poder Judicial va a ser subordinada por una cosa juzgada emanada del Tribunal Constitucional, entonces asistimos a una pérdida de la esencia misma del Poder Judicial como poder del Estado. Como manifiesta Juan Monroy Gálvez, "de ahora en adelante todas las sentencias expedidas por los jueces adscritos

\footnotetext{
47 SAGÚÉs, Néstor Pedro. La interpretación judicial de la Constitución. Segunda edición. Buenos Aires: Lexis Nexis, 2006, pp. 193 y ss.

48 Jorge Carrión Lugo, comentando este inciso señala: “Debemos señalar que el Poder Judicial no tiene independencia o autonomía en el aspecto económico(Art. $145^{\circ}$ Const.) ni en el control de la conducta funcional de sus integrantes(...)Pero sí constituye una de las garantías de la administración de justicia y a su vez se erige como un principio esencial de ésta: la independencia y autonomía de los jueces en el ejercicio de sus funciones jurisdiccionales". En: Tratado de Derecho Procesal Civil. Tomo I. Lima: Editorial Grijley, 2000, p. 38.
} 
Víctor Malpartida Castillo - Tribunal Constitucional vs. Poder Judicial

(A propósito de un proceso competencial)

al Poder Judicial, son capitis diminutio. Así, por ejemplo, si se expiden en un proceso ordinario, el cual por organización competencial no es revisado por el TC, solo producirá cosa juzgada, es decir, una inmutabilidad de segundo nivel. Y esto debido a que, para su desgracia, dicha sentencia no recibió ni recibirá un examen de validez y legitimidad que, como acabamos de aprender, solo puede ser dado por el TC"49.

\section{ASPECTOS CONCLUSIVOS}

4.1.- El Tribunal Constitucional en la STC 006-2006-PC/TC plantea el concepto de "cosa juzgada constitucional", con lo cual se cierra el círculo de la influencia y control del Tribunal Constitucional sobre el Poder Judicial y lo dice al final de la cita: "Sólo de esa manera un ordenamiento constitucional puede garantizar a la ciudadanía la certeza jurídica y la predictibilidad de las decisiones jurisdiccionales". Lo que no dice el Tribunal es que cuando se refiere a decisiones jurisdiccionales se tiene en mente "sus decisiones jurisdiccionales", interesando solo lo que ellos determinan como conveniente. Finalmente ellos -el Tribunal- son los que pueden establecer que es verdad y que no lo es.

4.2.- Se pone en discusión, además, la aseveración en cuanto a que los tribunales y jueces ordinarios no pueden contradecir ni desvincularse de las sentencias del Tribunal Constitucional, bajo el riesgo -señala el Tribunal- de vulnerar no solo los principios de supremacía y fuerza normativa de la Constitución, sino también el principio de unidad, inherente a todo ordenamiento jurídico, añadiendo a lo dicho que si fuera el caso así, se habría subvertido el ordenamiento constitucional en su totalidad, introduciendo elementos de anarquía en las relaciones entre el Tribunal Constitucional y el Poder Judicial. Esto es complementado, con lo dicho más adelante, cuando el Tribunal señala que en materia de procesos constitucionales, existe una relación de grado inferior del Poder Judicial con respecto al Tribunal Constitucional.

Lo cierto es que, como manifiesta Ana Cristina Neyra ${ }^{50}$, la afirmación del Tribunal implica equiparar a quien interpreta de manera suprema la Constitución con la Constitución misma, y conlleva a obligar a los

\footnotetext{
${ }^{49}$ MonRoy GÁLVEZ, Juan. «Poder Judicial vs. Tribunal Constitucional». En: ¿Guerra de las Cortes? A propósito del proceso competencial entre el Poder ejecutivo y el Poder judicial. Palestra del Tribunal Constitucional. 4 Cuadernos de Análisis y Crítica a la Jurisprudencia Constitucional. Domingo García Belaúnde (Coordinador) Editorial Palestra. Primera eduición. Lima 2007, p. 21.

${ }^{50}$ NeYra Zegarra, Ana Cristina. «La eficacia del proceso competencial». En: Gaceta Constitucional. No 3. Lima: Editorial Gaceta Jurídica, marzo 2003, p. 59.
} 
Víctor Malpartida Castillo - Tribunal Constitucional vs. Poder Judicial

(A propósito de un proceso competencial)

órganos de la judicatura ordinaria a un seguimiento de los precedentes y sentencias del Tribunal Constitucional sin posibilidad de contradecir o desvincularse. Llama la atención la autora citada, que ello no parece condecirse con la propia naturaleza del precedente a nivel de Derecho Comparado, donde puede un órgano jurisdiccional apartarse del precedente, haciendo uso del overruling o revocación del precedente, haciendo las precisiones y fundamentar las razones del cambio. En el mismo sentido de la autora anteriormente citada, Juan Monroy Gálvez tampoco encuentra una situación similar a la descrita de no apartamiento del precedente establecido por el Tribunal Constitucional, dentro del derecho comparado ${ }^{51}$.

4.3.- Otro punto controvertido y necesariamente discutible es en cuanto a la nulidad de las sentencias estimatorias en casos de amparo y cumplimiento del Poder Judicial. Lo cierto es que no solo se anula cualquier sentencia sino aquellas que constituyen cosa juzgada. Como manifiesta Ana Cristina Neyra ${ }^{52}$, se anulan decisiones sin entrar a evaluar las particularidades o detalles de cada proceso en donde se expidió las mencionadas sentencias, afectando a quienes no forman parte en el presente proceso y por tanto, planteando una situación de indefensión, vulnerándose el debido proceso de los justiciables ${ }^{53} 54$.

4.4.- Asimismo, se puede señalar que un modelo del constitucionalismo no debe suponer una extensión desmesurada de los poderes de los jueces constitucionales. Sin embargo, en un país como el Perú, en el cual, la tradición democrática -que es el mensaje y proyección del Estado Constitucional- no es desarrollada, sino al contrario, se encuentra en ciernes, ha hecho que el Tribunal Constitucional adopte una posición de control y de establecer lineamientos interpretativos discutibles en cuanto a la Constitución y a su propia función, viéndolas muchas veces como ex-

51 Monroy GÁlveZ, Juan: «Poder Judicial vs. Tribunal Constitucional». En: ¿Guerra de las Cortes? A propósito del proceso competencial entre el Poder Ejecutivo y el Poder Judicial. Palestra del Tribunal Constitucional. 4 Cuadernos de Análisis y Crítica a la Jurisprudencia Constitucional. Domingo García Belaúnde (Coordinador). Editorial Palestra. Primera edición. Lima 2007, pp.33-34.

52 Neyra Zegarra, Ana Cristina: Ob. Cit., p. 59.

53 Véase al respecto: JimÉnEZ VARGAS - MACHUCA, Roxana y ABANTO TORRES, Jaime David: «La abolición de la cosa juzgada». En: ¿Guerra de las Cortes? A propósito del proceso competencial entre el Poder Ejecutivo y el Poder Judicial. Palestra del tribunal Constitucional. 4 Cuadernos de Análisis y Crítica a la Jurisprudencia Constitucional. Domingo García Belaúnde (Coordinador). Editorial Palestra. Primera edición. Lima 2007, pp. 225 y ss.

54 De similar opinión es Luís Castillo Córdova (En: El Tribunal Constitucional y su dinámica jurisprudencial. Lima: Editorial Palestra, Setiembre 2008, p. 230).

55 Llanos, Marino. Prólogo a García Zárate, Oscar Augusto: Cuadernos de Lógica: Falacias. Segunda Edición. Lima: Editorial Mantaro, 1997. 
Víctor Malpartida Castillo - Tribunal Constitucional vs. Poder Judicial

(A propósito de un proceso competencial)

tensiones desmesuradas. Entonces, siempre es necesario que el Tribunal Constitucional recuerde que es intérprete de la norma constitucional, pero no es la Constitución misma, la cual no promueve que la justicia ordinaria siga a pie juntillas sus precedentes y sentencias sin posibilidad de cuestionamiento, atentando contra la independencia del Poder Judicial, y, en el caso concreto que comentamos, la seguridad jurídica y cosa juzgada -a la que el Tribunal le añade el adjetivo de constitucional-. Por tanto, sí se amenaza otros bienes constitucionalmente valiosos cuando no se advierte que la intervención del juez constitucional debe ser mesurada y con las particularidades que hemos reseñado anteriormente.

4.5.- Igualmente, cabe indicar que las falacias son -según el profesor Marino Llanos- "formas de razonamiento no válidas, pero que por su sentido, forma y contenido resultan muy engañosas y pasan normal e inadvertidamente como válidas en muchas argumentaciones jurídicas, políticasy de sentidocomún" ${ }^{55}$ Asimismo, García Zárate señala que “...las falacias nos engañan, haciéndonos admitir como válidos razonamientos que no lo son. El peligro de la falacia reside en que el error que quita valor al razonamiento permanece encubierto o disimulado. Como se comprende, un error visible sería detectado de inmediato. En las falacias los errores se hallan revestidos de una apariencia de corrección". Aclara seguidamente el profesor citado que "los lógicos usan el término falacia en un sentido más estricto o más técnico de error en el razonamiento: una falacia es un tipo de razonamiento incorrecto. Algunos razonamientos son tan obviamente incorrectos que no engañan a nadie(...)En lógica se acostumbra reservar el nombre de "falacia" a aquellos razonamientos que, aunque incorrectos, son psicológicamente persuasivos: una falacia es una forma de razonamiento que parece correcto, pero resulta no serlo cuando se lo analiza cuidadosamente". Por otra parte, se tiene que las falacias se dividen en dos clases, las formales y las no formales, ésta últimas denominadas también materiales o retóricas ${ }^{56}$.

Ahora bien, al parecer estamos ante una falacia fundamental - aunque por momentos podría pensarse en una mentira ${ }^{57}$ - elaborada por el Tribunal

56 GARCía ZÁrate, Oscar Augusto. Cuadernos de Lógica: Falacias. Segunda edición. Lima: Editorial Mantaro, 1997, pp. 7 y ss.

57 Como expresa el profesor Atienza, "hay una importante diferencia entre las falacias y las mentiras, las primeras pueden no ser intencionales"(ATIENZA, Manuel. La guerra de las falacias. Tercera edición. Alicante: Librería Compas, 2008, p. 226). Se hace alusión a esta distinción en atención a que el Tribunal Constitucional peruano actúa muchas veces inducido por una situación del país, en el cual frente a la inacción del Poder Judicial de desarrollo de los derechos fundamentales y de propender a la seguridad y predictibilidad 
Constitucional, falacia correspondiente al orden de las no formales o materiales, cuando señala que sus precedentes constitucionales vinculantes son de obligatorio cumplimiento e inmodificable, constituyéndose -entonces- en la Constitución misma y no en lo que le toca un intérprete de la misma, utilizando para ello aspectos como la "interpretación sistemática" del articulado constitucional y establecer en su Ley Orgánica y en el Código Procesal Constitucional, la condición de "intérprete máximo". Igualmente sucede con la instrumentalización de la "cosa juzgada constitucional", la cual subvierte la "cosa juzgada" emanada de la judicatura ordinaria, como consecuencia de dotar de un significado y contextualización distinta de la cosa juzgada constitucional obrante en el derecho comparado, como se ha visto en lo señalado por Néstor Pedro Sagüés.

Lo curioso de todo esto es que el actuar del Tribunal Constitucional, estaría dado por una interactuación con el Poder Judicial avasallado. Así, puede ser representativo de lo que se viene diciendo la Resolución de Jefatura $\mathrm{N}^{\circ}$ 021-2006-J-OCMA/PJ de fecha 13 de marzo de 2006 -citada en la propia resolución en comento aquí-, en la cual se dispuso: "todos los órganos jurisdiccionales de la República, bajo responsabilidad funcional, den cabal cumplimiento a los precedentes vinculantes señalados por el Tribunal Constitucional en sus sentencias dictadas en los Expedientes (...) $\mathrm{N}^{\circ} 4227-2005-\mathrm{AA} / \mathrm{TC}(\ldots)^{\prime \prime}$. Esto no haría sino corroborar lo que Vega Reñón señala en cuanto a que "la argumentación falaz se perpetra y desenvuelve en un marco no solo discursivo sino interactivo -donde la complicidad del receptor resulta esencial para la suerte del argumento-, de modo que la dualidad de sofismas y paralogismos presenta una curiosa correlación: el éxito de un sofisma cometido por un emisor trae aparejada la comisión de un paralogismo por parte de un receptor" ${ }^{58}$

Es cierto que luego de la Resolución de OCMA mencionada, el Consejo Ejecutivo del Poder Judicial, a través de un comunicado de fecha 4 de abril de 2006, desconoció los efectos normativos del precedente vinculante también mencionado. Sin embargo, el hecho mismo que el Poder Judicial no asuma su rol -situación que ha venido cambiando con las últimas gestiones-, de control constitucional activo, de generar sus propios precedentes vinculantes, de desarrollo de conceptos a través de su jurisprudencia, hace que pueda considerarse su actuar dentro de esa calidad de "falacia compartida".

jurídicas, entonces en este afán habría cometido más que una mentira intención de engañar) una falacia en su sentido de paralogismo.

58 VEGA REÑÓN, Luis: «La argumentación a través del espejo de las falacias». En: SANTIBÁÑEZ YÁNEZ, Cristián y MARAFIOTI, Roberto (Editores). De las falacias. Argumentación y comunicación. Bs. As.: Editorial Biblos, 2008, p.186. 